\title{
¿Existe una estrategia y evaluación adecuada para la enseñanza-aprendizaje de Katakana del idioma japonés con estudiantes mexicanos?
}

\section{Is there an adequate strategy and evaluation for Katana's teaching and learning of Japanese with Mexican students? Daisuke Kishi ${ }^{a}$}

\begin{abstract}
:
The main objective of this work is to find in Mexican students of Japanese a didactic strategy through some of the most common mistakes in learning katakana.

According to the result obtained, in principle, the mistakes in katakana were similar to those they had made in hiragana. However, the errors that were most frequently recorded in our Japanese students are phonetic and phonemic. It may be possible that, in most cases, the scarcity of these phonemes or sounds in Mexican Spanish prevents Mexican students from suffering from confusion in both comprehension and writing.
\end{abstract}

\section{Keywords:}

applied linguistics; teaching Japanese; phonetic interference; Katakana; Hiragana

\section{Resumen:}

Este trabajo tiene como objetivo principal encontrar en estudiantes mexicanos del japonés una estrategia didáctica a través de algunos de los errores más comunes en el aprendizaje de katakana.

Según el resultado obtenido, en principio fueron similares los errores en katakana a los que habían tenido en hiragana. Sin embargo, los errores que se registraron más frecuentemente en nuestros alumnos del japonés son de carácter fonético y fonemático. Es muy probable que, en la mayoría de los casos, la escasez de esos fonemas o sonidos en el español mexicano impida que los alumnos mexicanos sufran de la confusión tanto en la comprensión como en la escritura.

\section{Palabras Clave:}

lingüística aplicada, enseñanza de japonés, interferencia fonética, katakana, hiragana

\section{INTRODUCCIÓN}

El interés por estudiar japonés se ve en aumento cada día más no solo en este país, sino también a nivel mundial, probablemente debido a una amplia difusión de algunos aspectos de la cultura japonesa tradicional y moderna como su comida, el J-pop, los mangas o comics japoneses. Esta tendencia indudablemente se debe en mayor o menor grado al desarrollo continuo de las redes sociales como YouTube, Facebook, WhatsApp y demás.

Según la encuesta Survey Report on Japanese - Language Education Abroad 2018 [1], realizada por la Fundación Japón (Japan Foundation), se han registrado 142 países donde se estudia el idioma japonés. El número de alumnos del mencionado idioma alcanza aproximadamente 3.85 millones. Durante los últimos 39 años (del año 1979 al 2018) el número de aprendientes de japonés ha aumentado considerablemente, aunque el auge se registró en 2012; en otras palabras, 30.3 veces más que hace 39 años (Véase la FIGURA 1).



(Fuente: Survey Report on Japanese - Language Education Abroad 2018)

Con respecto al motivo por aprender el idioma japonés, ocupa el primer lugar "el interés por el animé, el manga, el J-POP, 
moda, etc." con un $66.0 \%$; le siguen "el interés por el idioma japonés" con un $61.4 \%$, "el interés en historia, literatura, artes, etc." con un 52.4\%, "estudiar en Japón" con un 46.7\%, "el turismo en Japón" con un $41.1 \%$, entre otros. Estas cifras coinciden en mayor o menor grado con la tendencia de nuestros alumnos de japonés en el Centro Universitario de Ciencias Sociales y Humanidades de la Universidad de Guadalajara. Cuando se refiere al tema de la enseñanza de una lengua extranjera, no se podrá dejar de lado solamente la falta de interés de los alumnos por el idioma o la poca dedicación de éstos, ni el comportamiento y capacidad de los docentes, ni el material de apoyo didáctico ni la infraestructura de la institución. Además de la insuficiencia en el material didáctico y en la infraestructura, según la FIGURA 2 [2], creemos que la metodología que se utiliza en el salón de clase y en las clases en línea puede ser un elemento muy importante, dado que el uso de un buen método y herramientas TIC apropiadas puede despertar el interés en los alumnos, o viceversa.

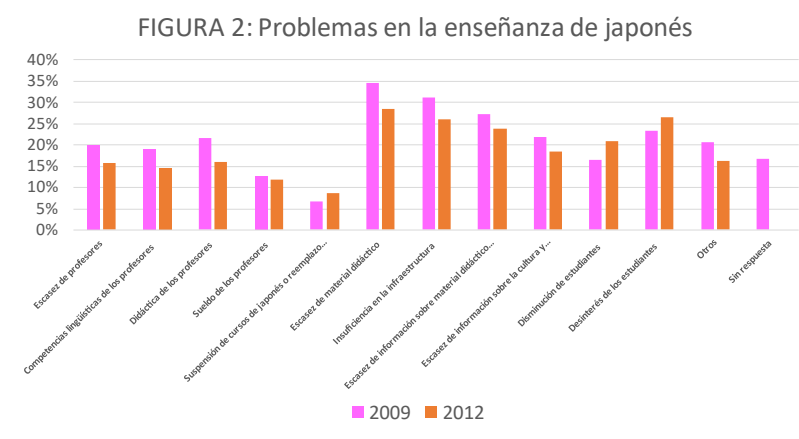

(Fuente: Survey Report on Japanese - Language Education Abroad 2012)

En la República Mexicana se enseña el japonés en 28 Estados incluyendo la Ciudad de México y su área metropolitana, en los cuales se encuentran registradas 156 instituciones y 3 más que dan clases en línea, según la información proporcionada en 2021 por la Fundación Japón en México [3]. Es muy probable que se impartan clases del idioma en más universidades o escuelas que no hayan proporcionado información a dicha fundación. Y los dos últimos años en la Universidad de Guadalajara, particularmente en el CELEX del Centro Universitario de Ciencias Sociales y Humanidades, se han registrado alrededor de 80 alumnos de japonés por semestre, si bien hubo un $20 \%$ más antes de la pandemia.

De hecho, no abundan estudios relacionados con este tema. El Comité de Educación de la Zona Metropolitana de Tokio, a partir de 2009, ha realizado investigaciones sobre la didáctica del japonés para promover una metodología adecuada para alumnos extranjeros de primaria y secundaria, residentes en Tokio. La metodología utilizada, si bien se refiere también a las letras hiragana y katakana, sigue siendo aún tradicional y está programada para niños y adolescentes extranjeros en general.

Jinnouchi [4] intenta buscar una didáctica mejor sobre katakana a través de las encuestas realizadas a 198 instituciones de japonés donde lo estudian extranjeros de distintas nacionalidades tales como de China, Corea, otros países asiáticos y países no asiáticos. Según el resultado de sus investigaciones, un $69.2 \%$ de los encuestados mostraron cierta dificultad en el aprendizaje de las letras katakana, mientras que se presentó tan solo un $7.0 \%$ de dificultad con hiragana. Lo interesante es que esta tendencia resultó variable dependiendo de la nacionalidad. Sorprendentemente en la vida cotidiana en Japón los hablantes de chino se quejan de cierta dificultad en la comunicación con katakana con un $90 \%$ de frecuencia. Por otra parte, el porcentaje de la dificultad en el aprendizaje de dichas letras baja hasta menos de $70 \%$ con los hablantes de coreano y de otros idiomas, cuya tendencia, según el autor, se debe a que existe tanto a nivel léxico como en la escritura una distancia enorme entre las palabras en katakana y en chino.

Nittono y Takeda (2010) [5] han hecho investigaciones analíticas sobre el tema con el fin de mejorar el rendimiento del aprendizaje de las palabras en katakana en estudiantes extranjeros de intercambio. Afirman que para ellos es difícil aprender las palabras en katakana por tres razones: en primer lugar, las mencionadas palabras no son tan conocidas para los aprendices como las de hiragana; en segundo, la mayoría de las palabras en katakana tiene origen en el inglés, por lo cual los hablantes no anglosajones o que no hablen bien el inglés tienden a presentar dificultad con esos vocablos; y por último se ha observado mal uso particularmente en las palabras en katakana con ambigüedad semántica. Y para evitar esos problemas los autores plantean tres consideraciones: 1) dejar de "katakanear" el japonés sin necesidad mientras que existan vocablos japoneses en kanji; 2) no exigir excesivamente a los alumnos el uso correcto para evitar el disgusto de aprender palabras en katakana; y 3) agregarles en lo posible las palabras de origen o la traducción no literal como en el caso de アイス コーヒー/aisukoohii/ (que no significa 'ice coffee', sino 'iced coffee'). Ambos estudios que acabamos de revisar parecen ser, a su vez, válidos, sin embargo, ninguno de ellos se trata de los casos específicos que pueden presentarse en el aprendizaje de las letras de katakana con hispanohablantes.

Como es sabido, el idioma japonés cuenta con tres tipos de escritura: hiragana, katakana y kanji. En el lenguaje escrito japonés se usan en combinación uno con otro, por ejemplo, como en 私はグアダラハラ大学で日本語を教えています - /watashi wa guadarahara daigaku de nihongo o oshieteimasu/ ('yo enseño el japonés en la Universidad de Guadalajara'). En este caso, las letras hiragana son は, で, を y えています, mientras que グアダラハラ es la única palabra en katakana. Y los demás caracteres: 私, 大学, 日 本語 $\mathrm{y}$ 教 son kanjis. Los caracteres chinos usuales en el japonés son actualmente 2,136 kanjis, según la Agencia Japonesa para Asuntos Culturales [6]. Por supuesto, en la educación superior se aprenden aproximadamente 1,000 kanjis más. Además, para llevar una vida culta en Japón se recomienda aprender hasta 5,000 caracteres. Ahora bien, las dos primeras son alfabetos, los cuales están formados por 46 letras silábicas, respectivamente. Los silabarios hiragana se pueden utilizar prácticamente para cualquier palabra y parte de la oración, sea sustantivo, adjetivo, adverbio, verbo o partícula, pero lo más común es que se usan para la terminación de los verbos y adjetivos, así como para todo tipo de partículas. En cambio, las letras katakana se utilizan 
principalmente para cualquier extranjerismo, aunque en él predominan los anglicismos y pseudoanglicismos. De hecho, los primeros extranjerismos, además de los chinismos como ラ ーメン /raamen/ く 老麺 ('fideo chino en caldo') o ギョーザ /gyooza/ < 餃子 ('empanadas chinas'), datan del siglo XVI. Llegaron primero los préstamos del portugués tales como カッ パ /kappa/ ('gabardina') < capa; パン /pan/ ('pan') < pão; カ ステラ /kasutera/ ('pastel sin betún') < pão de Castella, etc. Poco después llegaron las palabras del castellano como メリ ヤス /meriyasu/ ('ropa interior elástica') $<$ medias. En el siglo XVII introdujeron vocablos holandeses como コーヒー /koohii/ ('café) < koffie; ビール /biiru/ ('cerveza') < bier; ガ ラス /garasu/ ('vidrio') < glas; メス /mesu/ ('bisturi') < mes; カンフル /kanfuru/ ('alcanfor') kamfer, etc. A partir de la Era de Meiji (1868-1912), junto con la civilización occidental, entraron vocablos del inglés, francés, alemán, italiano, entre otros. Como ejemplos de los anglicismos podremos citar ホッ トケーキ/hottokeeki/ ('hot cake') < hotcake; エレベーター /erebeetaa/ ('elevador') < elevator; ラジオ/rajio/ ('radio') < radio, etc. Del francés se encuentran huellas léxicas tales como ズボン /zubon/ ('pantalón') < jupon [7]; シャンソン /shanson/ ('chanson') < chanson; フィアンセ /fianse/ ('prometido/a') < fiancé/fiancée; アベック /abekku/ ('pareja') < avec, etc. Del alemán entraron palabras como ガ —ゼ /gaaze/ ('gasa') < Gaze; カルテ /karute/ ('historia clínica') < Karte; アルバイト/arubaito/ ('trabajo de medio tiempo') $<$ Arbeit, etc. [8] (165-171).

Dentro de la categoría de los anglicismos existe lo que llamamos "pseudoanglicismos" o "anglicismos japonizados". Citaremos aquí algunos de los vocablos más comunes [9]: オ フィスレディ /ofisuredii/ ('oficinista femenina') < office lady*; クリームソーダ /kuriimusooda/ ('refresco de melón con helado de vainilla') < cream soda*; ジーパン /jiipan/ ('pantalón de mezclilla') < G pants*; ナイター /naitaa/ ('juego de béisbol nocturno') < nighter*; マザーコンプレッ クス /mazaakonpurekkusu/ ('mamitis') < mother complex*, entre otros. Cabe mencionar que se encuentran esos anglicismos abreviados tales como ビル /biru/ ('edificio') < ビルディング < building; プロ /puro/ ('profesional' / 'producción') < プロフェッショナル < professional / プロ ダクション< production; テレビ /terebi/ ('televisión') < レビジョン< television set, etc. También hay vocablos abreviados, compuestos por dos palabras: セクハラ /sekuhara/ ('acoso sexual') <セクシャル + ハラスメントく sexual harassment; パソコン /pasokon/ ('computadora personal') < パーソナル + コンピューター < personal computer; エア コン /eakon/ ('aire acondicionado') < エアー + コンディシ $\exists$ ヨーく air conditioner, etc. En este caso, normalmente están formados por las dos primeras sílabas de cada palabra inglesa transcrita en japonés.

Además de este uso, estos silabarios se usan también para onomatopeyas como ツルツル /tsurutsuru/ ('sedoso'), ビショ ビショ /bishobisho/ ('empapado'), o para enfatizar algunos nombres propios o nombres comunes, en particular a nivel comercial como en los casos de トヨタ/toyota/ ('Toyota') <
豊田, イトーヨーカドー/itooyookadoo/ ('Ito Yokado') < 伊 藤ヨーカ堂 [9]; セール/seeru/ ('oferta') < sale, etc.

Es importante también mostrar una tendencia actual de los vocablos en katakana que se usan con más frecuencia. De acuerdo con la encuesta realizada por el National Institute for Japanese Language and Linguistics, las palabras en katakana más usuales en el lenguaje escrito son como se señala en la TABLA 1. サービス /saabisu/ ('servicio'), システム /sisutemu/ ('sistema') y センター/sentaa/ ('centro') son unos de los vocablos más frecuentes del uso, entre otros.

TABLA 1: Tendencia actual de los vocablos en katakana más usuales en el lenguaje escrito

\begin{tabular}{|l|l|l|l|l|}
\hline $\begin{array}{l}\text { Orden de de } \\
\text { la } \\
\text { frecuencia }\end{array}$ & $\begin{array}{l}\text { Informe } \\
\text { Anual } \\
\text { Gubernamen } \\
\text { tal }\end{array}$ & $\begin{array}{l}\text { Palabra de } \\
\text { origen } \\
\text { (inglés) }\end{array}$ & $\begin{array}{l}\text { Revistas de } \\
\text { propagand } \\
\text { a }\end{array}$ & $\begin{array}{l}\text { Palabra de } \\
\text { origen } \\
\text { (inglés) }\end{array}$ \\
\hline 1 & サービス & service & センター & center \\
\hline 2 & システム & system & サービス & service \\
\hline 3 & シェア & share & スポーツ & sports \\
\hline 4 & エネルギー & energy & コーナー & corner \\
\hline 5 & リサイクル & recycle & コース & course \\
\hline 6 & センター & center & $\begin{array}{l}\text { ボランテ } \\
\text { ヘア }\end{array}$ & volunteer \\
\hline 7 & ネットワーク & network & ページ & page \\
\hline 8 & ガス & gas & バス & bus \\
\hline 9 & コスト & cost & テーマ & theme \\
\hline 10 & ベース & base & チーム & team \\
\hline
\end{tabular}

(Fuente: NINJAL, 2000) [10]

A pesar de muchas hipótesis y polémicas sobre el posible origen del idioma japonés, aún no se sabe de dónde haya llegado. Sin embargo, según una de las hipótesis quizá más probables, una de las lenguas austronesias como sustrato se mezcló posteriormente con alguna o algunas lenguas altaicas [7] (14-15). El japonés, antes del siglo VI, no contaba con el sistema de escritura, aunque en él abundaban expresiones orales. Y con la llegada del budismo a través de Corea en el año 538 introdujeron por primera vez en Japón los caracteres chinos llamados kanji. Al principio los utilizaban solo los sacerdotes budistas y en las familias de clase alta. En la Era de Nara (710-794) ya se encontraba un intento de sistematización fonética de dicha escritura, o más bien el inicio de la alfabetización. En otras palabras, con el préstamo fonético de los kanjis se intentaba transcribir los silabarios japoneses. Para un japonólogo bastaría con un ejemplo de 仏蘭西 /furansu/ ('Francia'), cuyo vocablo se conserva como en el caso de 仏語 ('idioma francés'). A esos silabarios "kana" se les llama manyoogana; se recibe esa nomenclatura porque se encontraban en la antología Manyooshuu ('Colección de las Diez Mil Hojas') [11].

Los silabarios hiragana tuvieron evolución a partir de los kanjis en el estilo "soosho", cuyas nuevas formas se difundieron con más popularidad en el siglo $\mathrm{X}$ entre las mujeres. Ese ejemplo se puede observar en seguida en Kokin 
waka shuu (Colección de poemas antiguos y modernos). Dicha obra fue editada en el año 905 bajo la orden del Emperador Daigo (114)

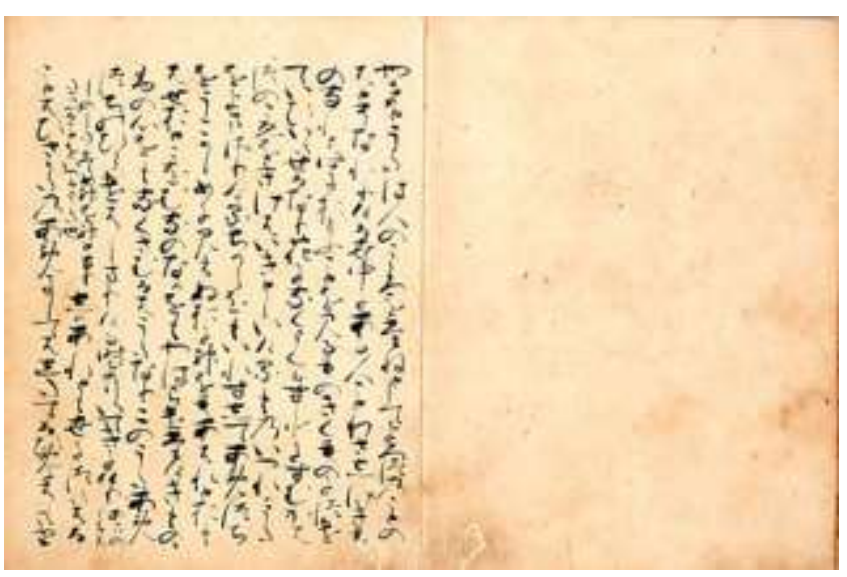

(Fuente: Kokin waka shuu. Recuperado de https://www.nijl.ac.jp/pages/articles/200704/)

Por otra parte, en la misma época que en el caso de hiragana, el silabario katakana también fue evolucionando. El modo de la evolución es distinto al de hiragana, ya que el motivo principal estaba en inventar las formas como signos fonéticos. Este silabario se elaboró, en la mayoría de los casos, de una parte de los kanjis. Algunas de las letras se utilizaban directamente de manyoogana, por ejemplo, como en チ /chi/ < 千; 二/ni/<二; 八 /ha/ <八; ヤ /ya/ <也, etc., sin embargo, como no cubrían esas letras todo el sistema fonético del japonés, es decir que eran una parte, por lo cual el mencionado abecedario recibió el nombre de katakana (< kata 'parcial' + kana 'silabario'), el cual quiere decir 'silabario parcial'. La evolución del silabario de katakana se puede observar en la TABLA 2.

TABLA 2: Posible evolución de los silabarios katakana

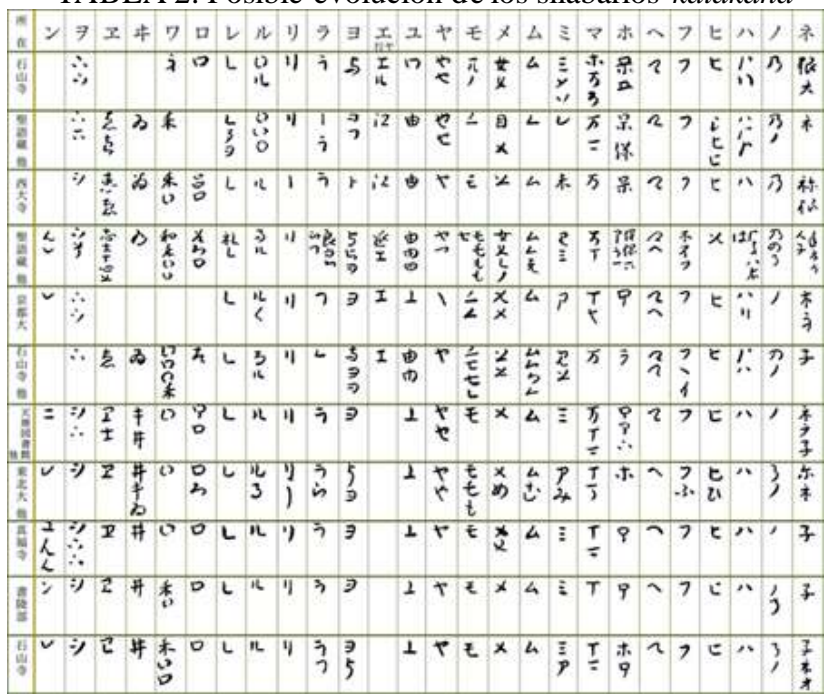

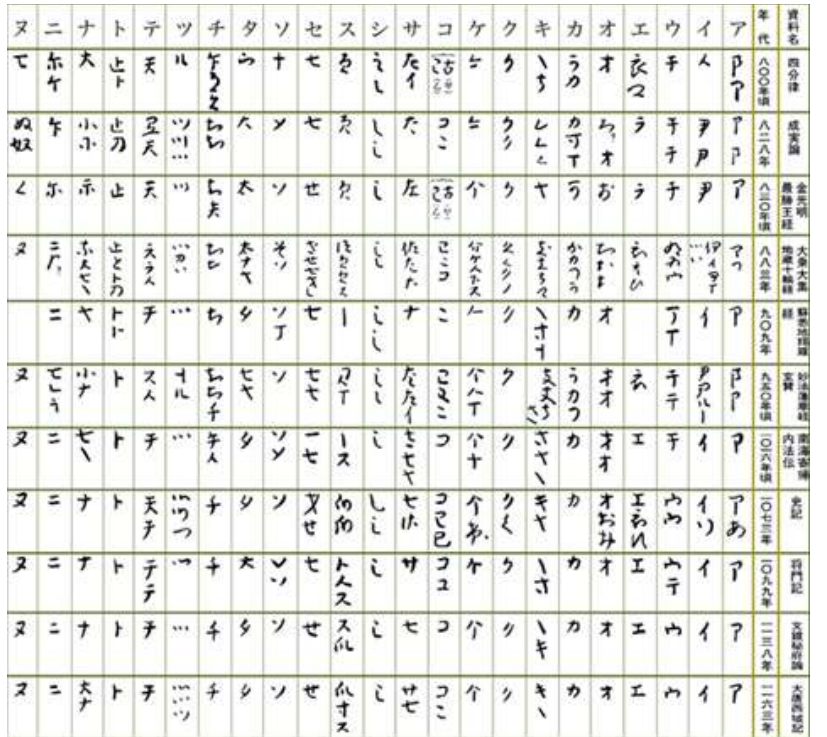

(Fuente: Sanseido Dural Dictionary. Recuperado de http://daijirin.dual-d.net/extra/katakana.html)

Como acabamos de mencionar, inicialmente las letras hiragana se usaban entre las mujeres, mientras que las de katakana las utilizaban los sacerdotes budistas para leer con menos dificultad las Oraciones budistas. A partir del año 1900 en que fue decretada Shoogakkoo ree shikoo kisoku (Reglamento sobre la Ejecución de la Orden de Educación Primaria), sigue la misma norma de los silabarios actuales. En esa época de Meiji era común que se escribiera en kanji, combinado con katakana, en particular en los documentos oficiales como se da a conocer en el siguiente ejemplo:

第一条 小学校二於テハ小学校令第一条ノ旨趣 テ児童ヨ教育スヘシ道徳教育及国民教育二関連セル事項 ハ何レノ教科目ニ於テモ常ニ留意シテ教授センコトヨ要 ス

知識技能ハ常二生活二必須ナル事項习選ヒテ之ヨ教授シ 反覆練習シテ応用自在ナラシメンコトヨ務ムヘシ

児童ノ身体 $习$ 健全二発達セシメンコトヨ期シ何レノ教科 目二於テモ其ノ教授八児童ノ心身発達ノ程度二副ハシメ ンコトラ要ス

男女ノ特性及其ノ将来ノ生活二注意シテ各々適当ノ教育 习施サンコトヨ務ムヘシ

各教科目ノ教授八其ノ目的及方法习誤ルコトナク互二相 連絡シテ補益センコトヨ要ス

(Fuente: Shoogakkoo ree shikoo kisoku, recuperada de http://www.mext.go.jp/b_menu/hakusho/html/others/detail/13 $\underline{18017 . h t m)}$

\section{OBJETIVOY METODOLOGÍA}

La enseñanza de una lengua extranjera no siempre puede aplicarse de igual forma a alumnos de cualquier país, sino que habrá que tomar en consideración características y factores 
lingüísticos y socioculturales de los alumnos extranjeros. A partir de nuestras investigaciones sobre la escritura hiragana [12], se ha comprobado que en estudiantes mexicanos o quizá de habla hispana existen ciertos errores comunes como en el caso de la confusión de la forma $い / \mathrm{i} /$ con り /ri/, así como en el caso de la confusión de las letras combinadas: じゃ /ja/, じ ゆ/ju/ y じょ/jo/ con las letras や/ya/, ゆ/yu/ y よ/yo/, la cual se debe en la mayoría de los casos a una falsa analogía fonética con la pronunciación en español. Por otra parte, en la etapa inicial del curso elemental, cuando los alumnos empiezan a aprender estas letras hiragana, se tiende a utilizar las letras romanas para facilitarles la comprensión de los sonidos de dicho alfabeto, lo cual tal vez les esté causando esas confusiones. En caso de katakana el hábito de los estudiantes mexicanos parece ser similar al de hiragana.

El objetivo del presente trabajo es investigar, con base en el estudio anterior sobre hiragana, así como con los datos obtenidos en estas investigaciones, la tendencia y problemas en el aprendizaje de las letras de katakana que se presentan en tiempo real o bien en aulas - en estudiantes mexicanos de japonés de nivel básico. De esta manera, creemos que sería más factible proponer una mejor didáctica que incluya una evaluación específica y apropiada para alumnos de habla hispana, en especial del Estado de Jalisco, en el que vivimos nuestra experiencia docente del japonés. Esto es una tarea urgente, dado que se ha observado que nuestros alumnos de japonés siguen erróneamente con el mismo hábito en el aprendizaje de las mencionadas letras.

En lo que concierne a la metodología, se puede considerar cualitativa, aunque se han utilizado dos métodos: el estudio cualitativo, enfocado en las observaciones directas en las clases y el estudio cuantitativo basado en una serie de encuestas con los estudiantes de japonés; el último se refiere a la investigación complementaria para comprobar la hipótesis planteada. En primer lugar, se aplicó a los alumnos de japonés un dictado de 24 vocablos en katakana previamente seleccionados, los cuales se mostrarán en el siguiente Apartado. La aplicación de esta investigación consiste en que los maestros los dicten tres veces con una velocidad más o menos normal; además la hoja de respuesta incluye una pequeña imagen en blanco y negro para que los encuestados o informantes tengan menos confusión o malentendido. La presente investigación se llevó a cabo, con la colaboración de unas profesoras de japonés, en el mes de mayo de 2015 en algunas clases de japonés del nivel básico de la Universidad de Guadalajara (UdeG) y la Universidad Autónoma de Guadalajara (UAG), dado que ambas son actualmente unas de las instituciones universitarias con más alumnos de japonés. Los informantes arriba mencionados están formados por 22 alumnos mexicanos (14 alumnos de la UdeG y 8 de la UAG); la mayoría de ellos son tapatíos y los demás vienen de otras regiones. Sin embargo, no creemos que el factor del lugar de origen afecte el resultado del estudio. En segundo lugar, la observación directa en las aulas será un método hasta cierto punto experimental con registro de una serie de variables y del "nivel micro social de concreción" como lo afirma Sánchez Puentes (1993) [13], ya que en muchos casos se podrá recolectar información con más espontaneidad y naturalidad, además de que el estudio se delimita a una mínima comunidad. Por lo tanto, el presente estudio se podrá considerar, en principio, cualitativo.

\section{RESULTADO}

Un par de los textos de japonés del nivel básico más usuales serán Minna no nihongo: I y II [14], en los cuales aparecen 172 extranjerismos sobre 817 palabras, con un 21\% de frecuencia [4] (94). Otro par muy usual serán Genki: I y II [15], en los cuales se encuentran 158 extranjerismos sobre 1,667 palabras en total, con un $9.5 \%$. Ahora bien, las palabras en katakana que se utilizaron para esta investigación son ウイ スキー ('whisky'), カメラ ('cámara'), キス ('beso'), パセリ ('perejil'), ヤマハ ('YAMAHA'), リスト ('lista') シーツ ('sábana'), パソコン ('computadora personal'), クリスマスッリー ('árbol de Navidad'), ソニー ('SONY'), ジーンズ ('pantalón de mezclilla'), チーズ ('queso'), ジャズ ('jazz'), ジュース ('jugo o refresco’), ジョギング ('trote'), シャープ ('SHARP'), テニスシュ ーズ ('tenis'), ショー ('show'), オープン ('inauguración'), シーズン ('estación'), キー ('llave'), パックマン ('Pacman'), ホットドッグ ('hot dog') y テ イッシュペーパー ('Kleenex o pañuelo desechable'). Fueron seleccionadas tanto por lo común en el japonés y el conocimiento de los alumnos de japonés como debido a las posibles fallas causadas por cuestión fonética y ortográfica, las cuales realmente queremos investigar.

Según los datos obtenidos en estas investigaciones, la mayoría de las palabras que pudieron contestar correctamente los alumnos está formada por dos o tres sílabas, como en los casos de キー (19 incidencias), リスト (17), カメラ (16), ソニー (15), キス (14), ヤマハ (14), パソコン (14), パセリ (13) y ショー (12). En cambio, en los vocablos compuestos tales como テニスシューズ o ティッシュペーパー hubo solo una respuesta correcta, respectivamente, si bien se registraron 6 respuestas favorables en クリスマスッリー y 4, en ホット ドッグ. Esta tendencia indica tácitamente que los aprendices del idioma japonés pueden captar con menor dificultad palabras con pocas sílabas, fáciles de escuchar.

Los errores ortográficos resultaron pocos, excepto en el caso de シ /shi/ y ツ/tsu/, cuya confusión o descuido ortográfico durante muchos años se ha observado con mucha frecuencia en las clases. De acuerdo con el estudio realizado sobre los problemas de hiragana [12], se presentó más frecuentemente la confusión de las letras diptongadas じゃ/ja/, じゅ/ju/ y じ よ/jo/ con las letras や/ya/, ゆ/yu/y よ/yo/, entre otros. Con las letras katakana también ocurrió el fenómeno similar como en los casos de ジャズ>ヤース; ジュース > ユース o ユス; ジョギング > ヨギング, es decir, el cambio de ジャ/ja/, ジ ユ / /ju/ y ジョ /jo/ a ヤ /ya/, ユ ᄀ /yu/ y ヨ /yo/, como afirma Montaner [16] (23) que "las aproximantes del japonés no se dan como en español”. La confusión de ズ /zu/ con ス /su/ fue sumamente común particularmente al final de la palabra, por ejemplo, como en ジーンズ > ジーンス o ジンス; チーズ 〉チース, チースー o シース ; ジャズ > ジャス o ジャ ース； シューズ>シュース, シュス o チュス；シーズ ン〉シースン, シスン o シイスン. Asimismo, se ha observado la confusión de ツ/tsu/ con ス /su/ en el vocablo ク リスマスッリー: ツリー>スリー. En las palabras con 
consonantes dobles se presentó la omisión de $ツ$ pequeña. Podemos citar パックマン >パクマン o パークマン; ホ ットドッグ>ホトドク, ホトドーク o ホトドグ, etc. Lo interesante es que estos últimos errores no son simplemente ortográficos, sino más bien fonéticos. Este fenómeno se debe indudablemente a la escasez de aquellos fonemas en el español; en otros términos, los alumnos intentan acomodar esos sonidos del japonés a través de los más similares a su oído, cuyo fenómeno lingüístico puede ocurrir casi siempre que se adaptan los préstamos en un idioma natal. Con vocales alargadas como en el caso de ウイスキー, hubo una omisión de la vocal final: ウイスキー /uisukii/ > ウイスキ/uisuki/. Este fenómeno coincide con el caso de hiragana como おいし い/oishii/ ('sabroso') > おいし /oishi/, según nuestras observaciones. Para los japoneses la distinción entre /kii/ y /ki/, entre /shii/ y /shi/ es fonemática.

\section{ENSEÑANZA-APRENDIZAJE ACTUAL EN LÍNEA}

En esta época de la pandemia nuestra forma de vida ha cambiado forzosamente debido al confinamiento prolongado. Esta tendencia no ha ocurrido solamente en el ámbito educativo, sino también a nivel comercial. En muchas empresas recurrieron a lo que se llama home office, cuyo trabajo ha contribuido a no aumentar posibles contagios del coronavirus. Por otra parte, se puede decir que las ventas en línea se encuentran en auge, desde los alimentos hasta todo tipo de mercancías. ¿Qué está pasando en el sector educativo? En México desde mediados de marzo de 2020 las escuelas e instituciones educativas prácticamente se encuentran cerradas, dicha situación ha impedido que las clases se impartan de manera presencial. De esta manera, actualmente la pedagogía está en una etapa de transición de la impartición de clases presenciales a la modalidad en línea. Aunque algunas instituciones o algunas carreras en las cuales se requiere la impartición de talleres o prácticas de laboratorio empiecen a recurrir a B-Learning, por cuestión del confinamiento debido a la propagación de COVID-19, nos enfocaremos exclusivamente a E-Learning, es decir, a las clases no presenciales con apoyo tecnológico y comunicativo. Los cursos en línea, como es bien sabido, se pueden dar por medio de interacciones sincrónicas y asincrónicas. Se podrá usar solo un tipo de interacción, pero es más aconsejable utilizar ambos, en otras palabras, combinar las clases sincrónicas con las asincrónicas, ya que en las clases sincrónicas se pueden utilizar, por ejemplo, Meet, Zoom, Teams, entre otras. En estas plataformas los profesores pueden transmitir sus conocimientos a los alumnos, pero no de manera tradicional. Este método se centra en el aprendizaje basado en competencias (ABC), el cual se define como "una estrategia educativa que pone en evidencia el aprendizaje de conocimientos, el desarrollo de habilidades y de actitudes requeridos para un desempeño o desenlace del acto educativo" (López, 2017) [17]. Ahumada (2013) [18] reitera que el modelo pedagógico actual depende del "cambio rol docente/rol estudiante, prácticas orientadas a competencias...evaluación basada en aprendizajes competenciales/herramientas TIC". Se requiere, pues, el manejo de las TIC, empezando por Power Point, Youtube o algunas páginas interactivas, cuyas herramientas se pueden considerar como fundamentales para las clases sincrónicas. En el caso de la enseñanza-aprendizaje de las letras katakana, la plataforma MARUGOTO [19] sería una de las opciones deseables, puesto que, igual que en caso de hiragana y kanji, permite a los alumnos aprender los trazos de manera interactiva, así como los vocablos usuales con las imágenes. También se puede utilizar paralelamente Kahoot en particular para repasar de manera divertida las letras o palabras en katakana. Este tipo de estudio permite que los alumnos aprendan esos vocablos con más naturalidad y relajación, lo cual sería prácticamente indispensable para este periodo de la pandemia. En muchos casos se pueden aprender al mismo tiempo aspectos culturales y sociales del país, por ejemplo, de Japón, como se observa en la siguiente imagen.

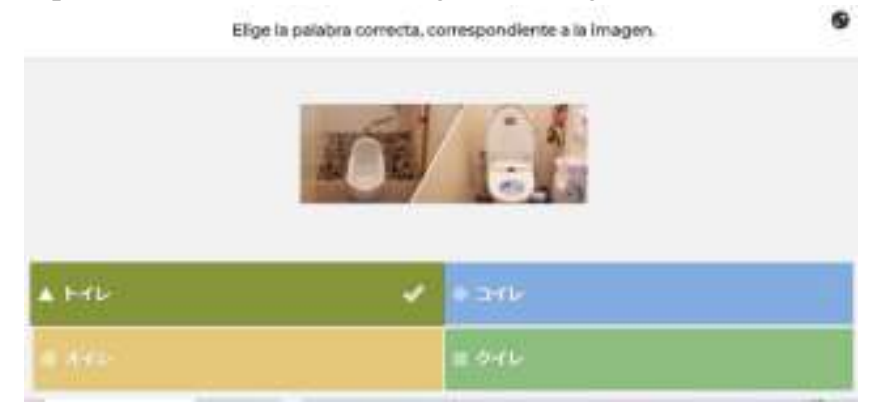

Recuperado en https://kahoot.it/challenge/27f157af-9d77-4578a83a-b3f3f9214dc4_1613447710231

En las clases asincrónicas, también existen varias opciones, pero probablemente Google Classroom será una de las plataformas más amigables, dado que es relativamente accesible a la mayoría de las herramientas. Por ejemplo, se puede dejar una tarea de escritura simplemente con las letras katakana como ejercicios y que los alumnos suban la tarea hecha en PDF. Después los docentes pueden corregir dentro del formato PDF y reenviarla a los alumnos. Sin embargo, lo mejor desde el punto de vista pedagógico sería que los maestros la imprimieran para corregirla en rojo o en otro color llamativo de su puño y letra. Así se podrá evaluar de la manera más correcta. Hay que advertir también que la evaluación no se puede limitar solamente a los conocimientos, llamada evaluación sumativa, sino que debe abarcar otras competencias tales como las habilidades y las actitudes (en este caso, particularmente la puntualidad y la responsabilidad); en otros términos, se puede considerar como una evaluación formativa (López, 2017). Otro punto importante al respecto sería la inclusión de las rúbricas en el programa de curso, en el sentido de que debe existir la transparencia entre los docentes y los alumnos. En este caso, se pueden citar los siguientes instrumentos: 
a) Responsabilidad y puntualidad en cuanto a la entrega del trabajo.

b) Escuchar al docente en las aulas sincrónicas.

c) Respeto al docente y a los compañeros en las aulas sincrónicas.

d) Retroalimentación después de la corrección u observación del docente.

\section{CONCLUSIONES}

De acuerdo con el resultado, los errores que se registraron con más frecuencia en nuestros alumnos de japonés son de carácter fonético y fonemático. Es muy probable que, en la mayoría de los casos, la escasez de esos fonemas o sonidos en el español mexicano impida que los alumnos mexicanos sufran de la confusión tanto en la comprensión como en la escritura. Por supuesto, habrá que reconocer que existen algunos fenómenos comunes entre los dos tipos de silabario, los cuales tienden a presentarse en los extranjeros o hispanohablantes; sin embargo, como afirma Jinnouchi [4], quizá sea una clave importante el darse cuenta de que la mayoría de los extranjeros sienten más dificultad en el aprendizaje de katakana que en el de hiragana. Investigar este punto será también uno de los próximos temas para los profesores de japonés en el extranjero.

Tomando en consideración dicho resultado o la tendencia a algunos errores frecuentes, es importante, y mucho más en esta época pandémica, que los docentes cambien la visión tradicionalista por procesos innovadores como el aula invertida (Flipped Classroom), la cual se basa fundamentalmente en las competencias tanto lingüísticas como actitudinales. Y seguramente el rendimiento del aprendizaje de los alumnos será mayor, ya que hay una participación más activa por parte de ellos. Por lo tanto, creemos que, actualmente y de ahora en adelante, sería una de las estrategias pedagógicas más viables en la enseñanza-aprendizaje de dichas letras. De la misma manera, la evaluación de las letras katakana, apoyada por las rúbricas, deberá ser más flexible, pero con base en las competencias de los alumnos.

Se espera que este estudio sirva de guía para los profesores y estudiantes del japonés no solo en este país, sino también en los pueblos de habla hispana. Además, creemos que desde el punto de vista diplomático, económico y cultural sería una de nuestras tareas más urgentes llevar a cabo de la manera más efectiva y funcional posible la enseñanza del mencionado idioma en esta tierra, ya que en octubre de 2018 se habían registrado en el país 1,228 empresas con inversión japonesa, según el Ministerio de Asuntos Extranjeros de Japón [20], actualmente con un incremento progresivo de ellas.

\section{REFERENCIA}

[1] Recuperado de https://www.jpf.go.jp/j/project/japanese/survey/result/d 1/survey2018/Report_all_e.pdf. Nos atrevimos a utilizar la última Encuesta 2018, ya que dicha investigación se lleva a cabo cada tres años.

[2] Japan Foudation (s.f.). Survey Report on JapaneseLanguage Education Abroad 2012. Recuperado de www.jpf.go.jp/j/project/japanese/survey/result/dl/surve y_2012/2012_s_excerpt_e.pdf.

[3] Fundación Japón en México (s.f.). dónde aprender el Idioma Japonés. Recuperado de https://www.fjmex.org/v2/site/seccion.php?id=68.

[4] Jinnouchi, Masataka (2008). "Nihongo gakushusha no katakanago ishiki to katakanago kyoiku" ("Conciencia y didáctica sobre katakana en aprendices de japonés"), Gengo to bunka (Lenguaje y cultura). 11. Nishinomiya: Kwansei Gakuin University. 47-60. Recuperado de http://kgur.kwansei.ac.jp/dspace/bitstream/10236/2868/ 1/20090907-4-27.pdf.

[5] Nittono, Osamu y Takeda, Akiko (2010). "Comments on Effective Learning of Katakana Words Commonly Used in Japanese Scientific and Technical Papers", Fukushima Daigaku Chiiki Soozoo (Creación regional: Universidad de Fukushima). 22, 1. Fukushima: Fukushima Daigaku Chiiki Soozoo Shien Center. 84102. Recuperado de http://ir.lib.fukushimau.ac.jp/dspace/bitstream/10270/3550/1/18-148.pdf.

[6] Fue modificada en 2010 la Ley sobre el número y uso de los kanjis, obligatorio para la educación básica y media. Agency for Cultural Affairs, Government of Japan. (s.f.). Joyokanjihyo (Tabla de kanjis básicos). Recuperado de. https://www.bunka.go.jp/kokugo_nihongo/sisaku/joho/ joho/kijun/naikaku/pdf/joyokanjihyo_20101130.pdf.

[7] Fue introducido este vocablo a finales de la Era de Edo (1603-1867) a través de las relaciones militares. Saeki, Umetomo (1977). Kokugo gaisetsu (Compendio del idioma japonés). Tokyo: Shueishuppan, 170.

[8] Okimori, Takuya (2012). Hajimete yomu nihongo no rekishi (Historia de la lengua japonesa como una primera lectura). Tokio: Bere Shuppan, 316-317.

[9] Es uno de los supermercados más grandes de Japón, fundado en 1920, con 183 sucursales nacionales y 14 en China. Recuperado de https://www.itoyokado.co.jp/company/iycsr/pdf/2014_ enq.pdf.

[10] NINJAL (2000). 「白書，広報紙等における外来語 の実態」 ("Situación de los extranjerismos en el Informe Anual, revistas de propaganda, etc."), Kokugoken no mado. 4. Recuperado de http://www.ninjal.ac.jp/publication/catalogue/kokken_ $\operatorname{mado} / 04 / 06$.

[11] Es la primera obra de las poesías japonesas, publicada probablemente después del año 759. Kato, Saji y Morita (ed.) (2000). Nihongo Gaisetsu (Compendio de la lengua japonesa). Tokyo: Ohhuu, 286. 
[12] Kishi, Daisuke (2013). "Algunos problemas de la escritura de hiragana del idioma japonés en el caso de estudiantes mexicanos", VI Foro Internacional de Especialistas en Enseñanza de Lenguas. ISBN: 978607-9136-88-8.

[13] Sánchez Puentes, Ricardo (1993). "Didáctica de la problematización en el campo científico de la educación", Perfiles Educativos, 61.64-78.

[14] 3A Network (2001). Minna no nihongo. I y II. Tokio: 3A Network.

[15] Banno, Ikeda, Ohno, Shinagawa y Tokashiki (2007). GENKI: An Integrated Course in Elementary Japanese. I y II. Tokyo: The Japan Times.

[16] Montaner Montava, María Amparo (2012). Caracterización lingüística de la lengua japonesa para hablantes de español. LynX, Annexa 21. Universitat de València. 19-33.

[17] López Carrasco, Miguel Ángel (2017). Aprendizaje, competencias y TIC. $2^{\mathrm{a}}$. edic. México: Pearson.

[18] Ahumada Torres, E. Mercedes (2013). "Las TIC en la formación basada en competencias", Revista de la Universidad de La Salle, 60. 141-157. Recuperado de https://ciencia.lasalle.edu.co/cgi/viewcontent.cgi?articl $\mathrm{e}=1356 \&$ context $=$ ruls.

[19] Véase https://a1.marugotoweb.jp/es/katakana.php.

[20] Ministry of Foreign Affairs of Japan (s.f.). Recuperado de https://www.mx.embjapan.go.jp/itprtop_es/index.html.

[21] Montaner (2007). "Algunos problemas para estudiantes hispanohablantes en el estudio de la lengua japonesa como L2", Lingüística en la red. Vol.5, Universidad de Alcalá. 1-9. Recuperado de http://www.linred.es/articulos_pdf/LR_articulo_13122 007.pdf.

[22] Tsujimura, Machiko (1995). "Nyuumonki niokeru hiragana gakushuu shidoohoo nikansuru ichikoosatsu" ("Una consideración sobre la didáctica de Hiragana en la etapa inicial - Método de aprender con juegos"), Kooza Nihongo-kyooiku (Curso de la enseñanza de japonés). Vol. 30. Tokio: Waseda Daigaku Nihongo Kenkyuu-kyooiku Center.

[23] Yamashita, N., Hata, Y. y Todoroki, Y. (2013). "Trial Instruction: Listening test of Katakana/words and Korean students' attitudes toward leaning Katakana words", Gengo bunka to Nihongo kyooiku. 45. 1929. 